\title{
From molecules to phenotypes? The promise and limits of integrative biology
}

\author{
Massimo Pigliucci
}

Departments of Botany, Ecology \& Evolutionary Biology and Philosophy, University of Tennessee, USA

Received July 27, $2001 \cdot$ Accepted May 6, 2002

\begin{abstract}
Is integrative biology a good idea, or even possible? There has been much interest lately in the unification of biology and the integration of traditionally separate disciplines such as molecular and developmental biology on one hand, and ecology and evolutionary biology on the other. In this paper I ask if and under what circumstances such integration of efforts actually makes sense. I develop by example an analogy with Aristotle's famous four "causes" that one can investigate concerning any object or phenomenon: material (what something is made of), formal (what distinguishes that particular object from others), efficient (how was the object made) and final (why was the object made). The example is provided by ongoing research on different aspects of flowering time in the model system Arabidopsis, a small weed belonging to the mustard family. I show that understanding how flowering time is controlled is an epistemologically different sort of question from why and how it evolved, and that the two research agendas can be pursued largely independently of each other. Toward the end, I propose that the real goal of integrative biology is to understand the boundary layers between levels of biological analysis, something to which modern philosophy of science can contribute significantly.

Ist integrative Biologie eine gute Idee, oder überhaupt möglich? In letzter Zeit existiert ein großes Interesse an einer Vernetzung der Biologie und der Integration von traditionell separaten Disziplinen, wie der Molekular- und Entwicklungsbiologie auf der einen Seite und der Ökologie und Evolutionsbiologie auf der anderen. In dieser Arbeit frage ich, ob und unter welchen Bedingungen solch eine Integration der Bemühungen tatsächlich Sinn macht. An einem Beispiel entwickle ich eine Analogie zu Aristoteles berühmten vier ,Gründen“, mit denen man jedes betreffende Objekt oder Phänomen untersuchen kann: Material (aus was ist etwas gemacht), formal (was unterscheidet das betreffende Objekt von anderen), effizient (wie wurde das Objekt gemacht) und final (warum wurde das Objekt gemacht). Das Beispiel wird durch die laufende Forschung an unterschiedlichen Aspekten der Blütezeit im Modellsystem Arabidopsis geliefert, einem kleinen Kraut, das zu den Kreuzblütlern gehört. Ich zeige, dass das Verständnis, wie die Blütezeit kontrolliert wird, eine epistemologisch andere Art von Frage ist, wie diejenige, warum und wie sie evolvierte, und dass die zwei Forschungsagendas weitgehend unabhängig voneinander verfolgt werden können. Zum Ende lege ich nahe, dass das wirkliche Ziel der integrativen Biologie ist, die Grenzschichten zwischen Bereichen biologischer Analyse zu verstehen, etwas wozu die moderne Wissenschaftsphilosophie einen signifikanten Beitrag leisten kann.
\end{abstract}

Key words: Arabidopsis - Aristotelian causes - functionalism - integrative biology - reductionism structuralism

*Corresponding author: Massimo Pigliucci, Departments of Botany, Ecology \& Evolutionary Biology and Philosophy, University of Tennessee, Knoxville, TN 37996-1100, USA, Phone: +1-865-974-6221; Fax: +1-865-974-2258;

E-mail: pigliucci@utk.edu 


\section{Introduction}

Readers of this essay will likely fall into two categories: for some (in my experience, mostly ecologists and some evolutionary biologists), what I am about to say is what they have tried to convince their more mechanistically oriented colleagues of for decades (mostly without making much of a headway). For others (molecular biologists and physiologists), I am certainly wrong and time will show that fuzzy evolutionary ecological questions will be replaced by specific answers provided by genomics, proteomics, or whatever other "omics" will be invented over the next decade or so. My goal here is therefore to provide some philosophical and empirical ammunition to the first group, and some food for thoughts to the second one. Given the contentiousness and importance (especially in terms of research funding and publication space) of the issue, I hope that both sides will at least pay attention and contribute to the discussion. I will start with a short historical introduction and will then try to set the problem in terms of the four "causes" proposed by Aristotle (384-322BC) as framing the conceivable classes of questions one can ask about a given subject matter (I will explain below why I think that this categorization is still very much valid today). Then I will analyze one example of possible integrative studies from my own research in detail, to explore the limits and usefulness of integrated biological research (I define "integrative biology" here as a multidisciplinary approach to biological investigations that includes molecular studies). I prefer to discuss one case study in depth rather than provide the reader with a series of sketchy examples because I think the case is best made by analyzing one of the most promising areas of integrative research, one that has been pursued for a long time using a model system. Since this article appears as part of a special feature on "plant population biology in a multidisciplinary context", the example is taken from that area of research. I will then end with some general considerations proposing where the balance between integrative and independent biological research may possibly lie and will conclude that biology is, like the rest of science (Dupré 1993), best thought of as a pluralist endeavor and that any attempt to force it into a monistic whole will be deleterious to making progress in our chosen subjects of study.

Even before Darwin there have been two traditions in biology: on the one hand, when faced with a biological structure of any sort, one could ask the question "What's it made of?" This tradition is known as structuralism, and the main biological disciplines with a marked structuralist outlook are much of developmental biology, molecular biology, physiology, and cell bi- ology. On the other hand, some people are more interested in questions of the sort "What's it for?" Ecology, evolutionary biology, and functional morphology fall into this group, traditionally defined as functionalism.

Structuralism and functionalism have been at ideological odds since the beginning (Rieppel 1990). One of the most famous battles in this respect is still regarded as a textbook example by historians of science. Georges Cuvier (1769-1832), the great French anatomist and father of paleontology, was a functionalist. He was not an evolutionist (he lived before Darwin), but he was convinced that the main goal of biology was to understand the function of every organ designed by the Creator. One of his pupils, Etienne Geoffrey Saint-Hilaire (1772-1844), thought otherwise. Geoffrey studied things like the change in structure of the bones of the middle ears in mammals as compared to the analogous bones in reptiles. Geoffrey did entertain some limited concept of evolution, but he endorsed the opinion that structures have logical priority over the functions they carry out; according to him, without a structure there is no function.

Let us fast forward in time and consider the socalled neo-Darwinian synthesis of the 1930s and 40s (Mayr \& Provine 1980). It was carried out essentially by organismal biologists, i.e., by ecologists and evolutionists (with help from some organismally oriented population geneticists). Names such as Dobzhansky, Mayr, Simpson, and Stebbins, among others, squarely fall in the functionalist (now evolutionist, as opposed to Cuvier's creationist version) camp. They wanted to know how natural selection shaped organisms, regardless of the intricate details of their structures. But a parallel biology was taking shape thanks to the work of, for example, Morgan, Beadle \& Tatum, McClintock, and Watson \& Crick (Sturtevant 1965). These people were not really interested in the evolution of things, as much as in peeking within organisms to see how they were made, in perfect structuralist tradition.

The contemporary view, pushed by several authors (including, to some extent, myself: Callahan et al. 1997) and certainly by the major Federal granting agencies in the US and to some extent in Europe, is that structuralism and functionalism can converge when we focus our attention on a few model organisms (Kellogg $\&$ Shaffer 1993). The three major ones are the fly (Drosophila melanogaster), the worm (Caenorhabditis elegans) and the plant (Arabidopsis thaliana) (see chapter 8 in Schlichting \& Pigliucci 1998).

\section{Four questions and a model system}

One of my interests during the past few years has been to understand different aspects of the relatively simple phenomenon of flowering time in plants using the little 
weedy mustard Arabidopsis as a model system (Pigliucci 1998, Mitchell-Olds 2001). Since I have worked at different levels of the biological hierarchy, I hope to convince both classes of readers mentioned above that I am coming to this analysis with the least amount of bias: after all, I am an organismal biologist who has made a career of doing integrative biology.

The first issue to address is to clarify what it means to "understand" flowering time (or anything else in biology). I submit that it means to answer four more or less distinct questions, which I will argue are directly analogous to Aristotle's famous "causes" (Box 1: Aristotle 384-322BC): 1) What genes are involved in controlling flowering time? (I.e., what are the elements or "material causes" of the phenotype?) 2) What, if anything, is special about the focal organism (say, Arabidopsis thaliana) in the way flowering time is controlled and expressed? (I.e., what is the "formal cause" of flowering in that taxon, which is a way to ask to what extent the developmental phenomena controlling flowering time in $A$. thaliana are generalizable to other species.) 3) How did differences in flowering time evolve to begin with? (I.e., what are the "efficient causes" of the currently observable phenotypes?) And 4) Why is it that $A$. thaliana shows certain flowering schedules instead of others? (I.e., what are the "final causes" that determine flowering time?) I will examine each of these in turn.

\section{Material causes - What genes?}

Part of the answer to the first question is emerging from a large effort by molecular biologists to characterize the biochemical pathways controlling different aspects of flowering time. Obviously, this kind of data goes a long way toward answering the "what genes?" question.

Box 1. A handy-dandy guide to Aristotle's causes.

Material cause - Addresses the elements out of which an object is made. E.g., the bronze of which a statue is made, or the DNA, organelles, and cell types involved in a biological process such as flowering.

Formal cause - Addresses the expression of what an object is. E.g., the particular person represented by a statue, or the developmental processes leading to flowering.

Efficient cause - Addresses the means by which an object is made. E.g., the sculptor who shaped the statue, or the evolutionary processes leading to a certain flowering schedule.

Final cause - Addresses the end (not necessarily in a conscious sense) to which the object is made. E.g., the motivation behind sculpting the statue, the ecological niche that a certain flowering schedule allows an organism to occupy.
For example, using the vast literature available on plant photoreceptors as a starting point (Furuya 1993, Furuya \& Schafer 1996, Quail 1997, Smith 2000), I investigated the environment-dependent phenotypic consequences of mutations striking key photoreceptors in charge of the so-called "shade avoidance" response in Arabidopsis. Shade avoidance is a type of phenotypic plasticity that has been demonstrated to allow a plant to regulate its life history and change its development and morphology in order to better cope with the presence of neighbors competing for light (Givnish 1982, Ballarè 1999, Weinig 2000, Donohue et al. 2001, Callahan \& Pigliucci 2002). Plants are able to sense the ratio between the red and far red components of the light spectrum. When the ratio is close to one, this indicates normal sunlight. But when the surrounding vegetation is growing, an increasing percentage of the red light is absorbed because it is photosynthetically useful while the far red is simply reflected away by leaves. This lowered R:FR ratio, detected by specialized photoreceptors known as phytochromes, triggers a series of developmental changes that are collectively known as the shade avoidance syndrome. Included in these are earlier flowering, diminished branching and increased elongation of the main stem, all characteristics that are thought to be adaptive in order to escape from neighbors' shading or competition (Dixon et al. 2001, Donohue et al. 2001, Tucic \& Stojkovic 2001).

My group demonstrated that not only the phytochromes control the shade avoidance phenotype and alter flowering time only in specific environments (Fig. 1), as predicted on the basis of our knowledge of the physiology and molecular biology of shade avoidance, but that these changes have indeed fitness consequences that are also environment-dependent, thereby confirming that this type of plasticity may be the result

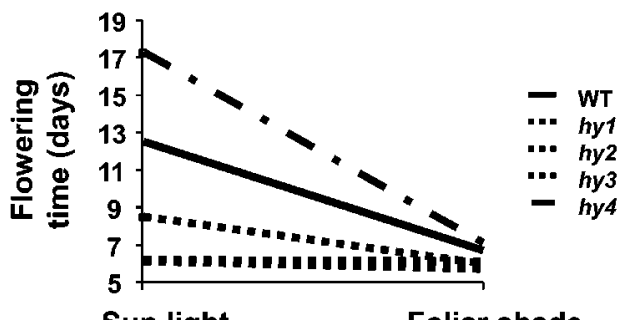

Fig. 1. An example of experimental study of shade avoidance in Arabidopsis. Flowering time reaction norms in response to sun light and foliar shade of a wild type (WT) and of four mutant lines: three genotypes damaged in phytochrome-mediated photoreception (responsive to the R:FR ratio), hy1-3, and one genotype damaged in blue light photoreception (hy4). Notice how the mutants show an altered plasticity to the environmental cue, respectively with decreased or enhanced shade avoidance. (Pigliucci \& Schmitt 1999). 
of a process of adaptive evolution (see also Dudley \& Schmitt 1996, Pigliucci \& Schmitt 1999, Schmitt et al. 1999). This sort of study can get exceedingly complex once we take into account multiple environmental factors and interactions among genes. For example, Callahan et al. (1999) investigated the reaction norms of single and double mutants affecting light perception in Arabidopsis when exposed to combinations of light quantity and water stress. They demonstrated complex epistatic interactions that hint at a possible coevolution of adaptive responses to high light and drought (which co-occur under field conditions), as well as widespread pleiotropic effects which indicated high levels of genetic redundancy (where similar functions are carried out by several molecules) among the battery of Arabidopsis photoreceptors.

A different approach to the genetics of flowering time investigates how difficult it is for natural populations to genetically alter their phenological schedule, i.e., what kinds of genetic constraints may be imposed on the action of natural selection (Wagner \& Altenberg 1996). Camara et al. (Camara \& Pigliucci 1999, Camara et al. 2000) conducted mutation-selection studies to see if they could alter the flowering time of Arabidopsis and how this would affect other traits that are genetically correlated with the focal one. They found that different doses of mutagen (EthylMethane-Sulfonate, EMS) did not appreciably change the genetic correlation between flowering time and number of leaves produced during the vegetative phase, a correlation that is also observed in natural populations (Mitchell-Olds 1996). This imposes a

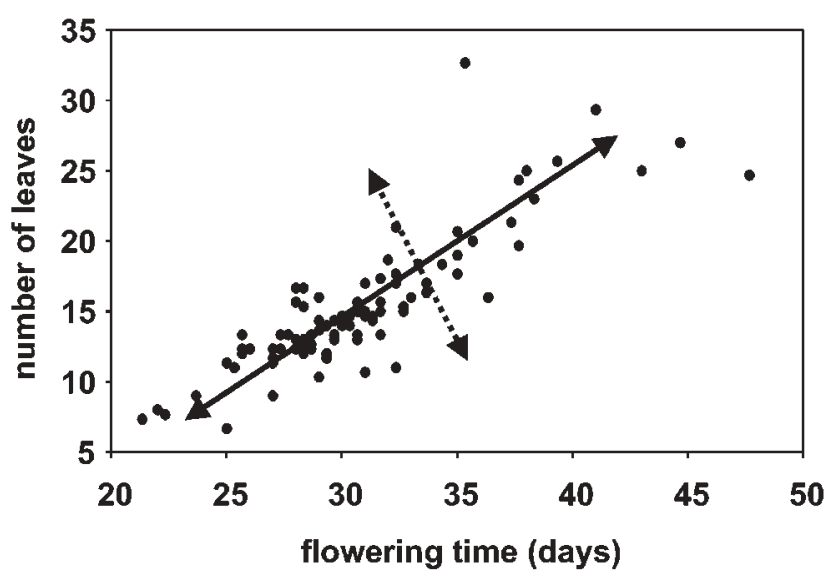

Fig. 2. Natural genetic variation for flowering time and number of leaves under standard laboratory conditions in a population of Arabidopsis thaliana (each dot represents a genotype). The two axes show the directions in phenotypic space of expected preferential response to selection (solid line) and of no response to selection (broken line). A selection experiment actually carried out confirmed these predictions. (Camara \& Pigliucci 1999, Camara et al. 2000). marked constraint on the ability of this plant to respond to selection, with an evolutionary response possible only by both traits simultaneously (i.e., there is no likelihood of independent evolution) and only in certain preferential directions in phenotypic space (Fig. 2).

Arabidopsis can also be conveniently used to investigate the number, location, and interactions among genes controlling flowering time (or any other trait) by employing a set of Recombinant Inbred Lines (RILs) between two strains differing widely for their phenology. The lines are mapped for molecular markers that can then be used to identify the genomic regions affecting the phenotype of interest (QTL, Quantitative Trait Loci, e.g., Kowalski et al. 1994, Kuittinen et al. 1997, Stratton 1998, Juenger et al. 2000).

So, the "what genes?" question can be addressed by identifying specific genes affecting a given phenotype in natural populations, by studying their pleiotropic and epistatic effects as well as their actual fitness consequences, and by characterizing how their presence limits the possible range of action of natural selection. However, notice how identifying the specific genes controlling flowering time and mapping their position on the chromosomes does not actually add much to the evolutionary ecological understanding of the function of shade avoidance, since the latter question can be pursued independently as long as one assumes that there are some genes that make the phenotype possible, regardless of how many they are and where they are located in the genome. In this sense, a classical statistical treatment (as in quantitative genetics) of the genetic basis of the phenotype of interest is all that is needed to pursue research on the evolution of the phenotype (but not, of course, of the evolution of the genes themselves).

\section{Is A. thaliana special? - On formal "causes" of phenotypes}

The second broad question that one can ask about flowering time is: how specific are its mechanisms to A. thaliana? (Aristotle's formal "cause" is not as much a cause as it is a description of the defining characteristics of an object.) Or, to put it into another fashion, is there something special - as far as this trait is concerned - in being the particular taxon Arabidopsis thaliana (or even the particular lab lines normally used for research on this species)? One of the advantages of using this model system is that it is easy enough (though not many people have done it so far) to expand research efforts toward close relatives, presumably sharing most but not all of its genetic machinery (Jonsell et al. 1995, Kamm et al. 1995, Tsukaya et al. 1997, Koch et al. 1999, Koch et al. 2001). It is important to understand the degree of uniqueness of model 
systems to see if and to what extent one can generalize results obtained by studying them. Other ecotypes of A. thaliana (different from the standard lab lines), close relatives such as Arabidopsis hirsuta, and more distant ones such as various species of Brassica can be used to see if the same basic genetic machinery produces similar developmental results and what, if anything, is distinctive of $A$. thaliana in this respect.

For example, Fig. 3 demonstrates that even if we limit the scope of our investigation to $A$. thaliana, different ecotypes apparently do things in quite a different way, showing that there must be "formal causes" distinguishing even the standard lab lines from most natural populations. The data were collected from the Arabidopsis Information Management System database (www.arabidopsis.org) and summarize the effect of vernalization (exposure to cold) on distinct populations. Depending on the life history of a population (spring ephemeral or winter annual) the behavior is very different (Jones 1971, Napp-Zinn 1985), though presumably the same basic molecular machinery is present in all cases. Specifically, winter annuals (which overwinter as rosettes and flower in the spring) flower much later if they are not exposed to cold when compared to spring ephemerals (which overwinter as seeds and also flower in the spring). Obviously, this variation must be caused by regulatory genes controlling the plasticity of flowering time in response to specific environmental stimuli, although which loci are actually associated with naturally occurring variation in this species is an issue that has just began to be addressed (Alonso-Blanco et al. 1998, Stratton 1998).

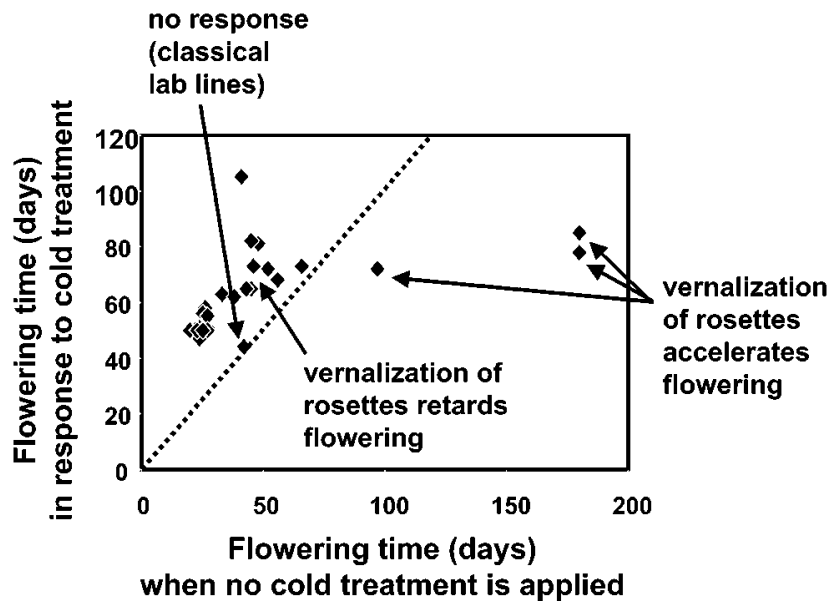

Fig. 3. Variation in plasticity of flowering time to cold treatment among different populations of $A$. thaliana accessible from the AIMS database. This shows not only that populations (individual points) cluster in distinct, ecologically definable, areas of phenotypic space, but that the lab lines are significantly different from most natural populations and that therefore results obtained using standard lines are only partially generalizable. (Data from www.arabidopsis.org).
Things become even more complex and interesting when we compare early and late flowering $A$. thaliana with other species of Arabidopsis (though the exact phylogenetic relationships of these taxa are still under considerable revision: Koch et al. 1999, 2000, 2001). Reaction norms for flowering time show that early flowering $A$. thaliana behave similarly to the closely allied $A$. petraea, while late flowering $A$. thaliana are more similar to distantly related species such as A. griffithiana and A. pumila (Pigliucci et al. 1999). This hints at a more prevalent role of functional ecology than evolutionary history (Westoby et al. 1995) in shaping this trait in at least this group of plants, which could be a more widespread phenomenon than usually appreciated.

Notice that comparative studies of this sort can be conducted largely independently of knowledge about the specific genetic mechanisms controlling flowering time in A. thaliana or any of its close relatives, as indeed they have been for quite a long time in many other groups of plants (and of animals for other traits). While I do not wish to push the point and claim that knowledge gained from studies of the first or second question (or indeed the third and fourth to which we will turn shortly) is unnecessary while pursuing different questions from that one for which that knowledge was gathered, I also think that the interconnectedness of different fields of inquiry within biology has been greatly exaggerated.

\section{What evolution? - On efficient causes}

The third general question we can ask is about the evolution of flowering time. In this case one has to use the phylogenetic comparative method (Harvey \& Pagel 1991, Martins 2000, Posada \& Crandall 2001, Rohlf 2001) to trace the evolution of the focal character and of related traits in Arabidopsis thaliana and close relatives. This is not an easy enterprise for a variety of reasons, including the already mentioned difficulty to reconstruct reliable inter-specific phylogenies within the Brassicaceae family (Koch et al. 1999, 2000, 2001), the added complication of doing so intra-specifically (Vander-Zwan et al. 2000, Posada \& Crandall 2001), and a variety of other problems plaguing a complex field of inquiry in which historical reconstruction plays a more important role than direct experimental manipulation (Gittleman \& Luh 1992; Westoby et al. 1995, Lee 1999, Omland 1999, Ackerly 2000).

Be that as it may, Pollard et al. (2001), for example, proposed a hypothesis of historical relationships among several accessions of $A$. thaliana from Scandinavian countries and between these and close relatives of 


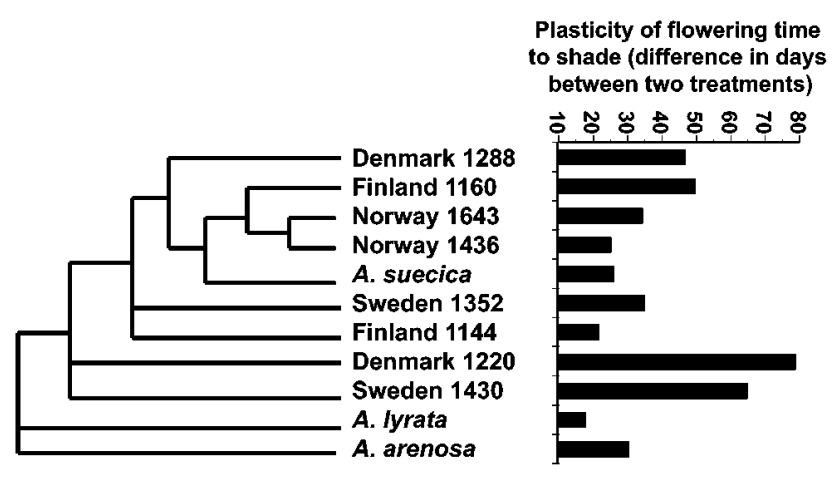

Fig. 4. Evolution of plasticity of flowering time in response to foliar shade in serveral populations of $A$. thaliana and a few closely related species (A. suecica is a hybrid between $A$. arenosa and $A$. thaliana, which is why it clusters inside the $A$. thaliana clade in this maximum likelihood phylogeny based on the sequencing of three intergenic chloroplast regions). Notice how plasticity changes dramatically throughtout the phylogram, althought there is a tendency of closely related taxa to show a similar magnitude of response to the environment. Numbers next to provenances refer to the catalog number of the accessions according to www.arabidopsis.org (Pollard et al. 2001).

A. thaliana and used it to determine the rates and patterns of evolution of several characters, including flowering time and its plasticity to foliar shade. Fig. 4 illustrates the changes in the plasticity of flowering time throughout the clade considered, showing several reversals and the fact that closely related accessions don't necessarily have similar plasticities. This led the authors to conclude that plasticity can evolve very rapidly, though in this case it is not clear if this is because of strong selection or of pronounced genetic drift.

Pollard et al. (2001) also traced character co-evolution on the phylogeny, for example showing that plasticity of flowering time measured in response to daylength changed through time following an inverse relationship with the same character measured in response to light quality, indicating that the two plasticities (of the same trait) were evolutionarily linked in a previously unforeseen fashion. The basal nodes of the clade considered by these authors tended to be characterized by early flowering in reaction to daylength and late flowering in reaction to light quality, while more recently branched nodes showed the opposite pattern, imparting a directionality to the evolution of these two traits that remains to be explained on either historical or functional grounds.

The question raised above of genetic constraints acting on flowering time in Arabidopsis (see the material cause section) can be usefully assessed from a different perspective in terms of future evolutionary trajectories (i.e., in terms of the equivalent efficient causes). Camara \& Pigliucci (in prep.) have attempted to select along and against the directions of the existing genetic constraints in both natural populations and populations whose genetic variation had been artificially augmented by mutation (Fig. 2). The lines selected along the main diagonal, i.e., along the "constraint", responded very rapidly to selection, immediately yielding statistically significant differences with their parental stocks. However, when we tried to select away from the main diagonal the plants did no better than the unselected controls, indicating that the genetic constraint described above indeed has the sort of limiting effects on the response to selection that would be predicted by quantitative genetics theory.

The study of the evolution of a character can be largely descriptive, as is often the case with the phylogenetic comparative method, or it can test specific hypotheses about the directionality of the change. However, even when genetics factors into the equation, it is at the statistical level of quantitative genetics and independently of which specific molecular sequences happen to be involved in the process and for which proteins they code. Once again, a large amount of research can be conducted within each "cause" with little reference to the other ones.

\section{What ecological context? - Final causes in biology}

The last question on our list concerns the ecological context of variation in flowering time, Aristotle's final cause because it answers the question of why we observe what we observe (needless to say, "why" and "final" here don't carry any teleological implications, as they did for Aristotle). This can be addressed at two scales: broad geographical variation and micro-environmental variation. At a broad scale, if one examines a geographical map of the distribution of $A$. thaliana in its natural range (throughout Europe and parts of Asia), one immediately notices that winter annuals tend to occur in regions characterized by mild winters, while spring annuals appear where conditions are harsher. A working hypothesis to explain this pattern is that winter annuals can only survive if the conditions are not harsh enough to kill their rosettes, but that on the other hand they enjoy an advantage over spring annuals because they have a head start on the competition at the beginning of the season (they are ready to switch to the reproductive phase while most other things are about to germinate). This is predicted by plant life history theory and has actually been demonstrated in several other instances (Silvertown 1988), although the case for A. thaliana is at the moment only circumstantial.

At a smaller scale, Callahan \& Pigliucci (2002) conducted a two year-two site field study of flowering time and other traits to get a better understanding of the ecology of and selection operating on this plant in the field. We started out by demonstrating significant 


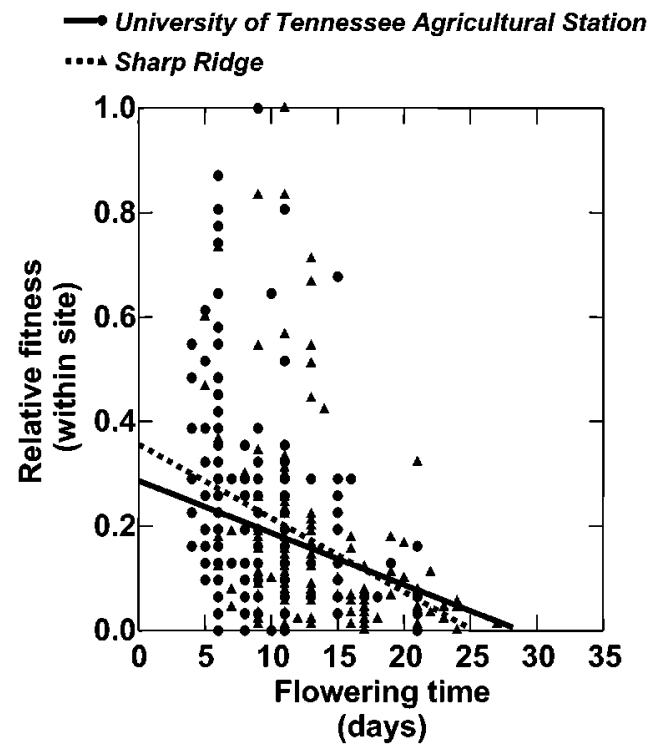

Fig. 5. Selection on flowering time under field conditions in two populations of $A$. thaliana collected in Knoxville, Eastern Tennessee (about 10 miles from each other). The slope of the two regression lines, indicating strong directional selection in favor of early flowering (presumably to escape competition) are not significantly different from each other. This sort of data can help answer the question of why we observe certain patterns of flowering time in natural populations (Aristotle's final cause). (Callahan \& Pigliucci, 2002).

variation both among sites and among years for flowering time and a host of related life history and morphological characters. We then used these data to estimate selection pressures on flowering time. Fig. 5 shows some of our findings of intense directional selection for early flowering (negative slopes of the two regression lines). This is likely the result of the fact that Arabidopsis in the wild faces intense competition, and early flowering is a typical strategy to escape it. This is in accordance to the ecological characterization of this species as a ruderal opportunistic weed (Grime 1974, Grime et al. 1986).

Studies of natural selection are not very useful unless they are repeated not only over several locations, but over a period of time (Kingsolver et al. 2001), given the known tendency of selection pressures themselves to vary spatially and temporally (Bell \& Lechowicz 1991, Lechowicz \& Bell 1991, Stratton 1995, Stratton \& Bennington 1996, 1998). We repeated the selection experiments in two years and in two locations, while simultaneously measuring selection on flowering time and on the genetically correlated character leaf number. The results were remarkably consistent, once again highlighting the constraint existing on the evolution of these traits discussed above, given that in all years and places selection pushes for early flowering and more leaves, a combination that the genetic architecture of these plants simply cannot achieve.
It should be clear that while recognizing constraints certainly helps in understanding the kind of response to selection that plants exhibit, it is also true that again only a high level, quantitative genetic analysis of the problem is strictly necessary here. Knowledge of the specific genes affecting flowering time and leaf production - while a worthwhile enterprise in itself - is no more called for in order to characterize the ecology of flowering time then it is to study its evolution, as long as some genes with the proper characteristics are present in the population. Furthermore, the question of the small and large geographical (or temporal) scales of action of selection does not impinge at all on the genetics underlying the system, since natural selection is quantified as a correlation (another statistical measure) of a trait with reproductive fitness (Lande \& Arnold 1983, Rauscher 1992).

\section{Toward a moderately integrated biology}

I have tried to make the argument, and to illustrate it from actual research examples focusing on understanding flowering time in the weedy mustard plant Arabidopsis, that scientific puzzles can be approached by asking four different kinds of questions, each of which is most appropriately probed by a distinct discipline or group of disciplines, such as molecular genetics, developmental and comparative biology, ecology, or evolution. These questions are conceptually largely independent of each other and, while cross-fertilization is often productive, distinct research agendas and traditions can be carried out within each discipline. More in general, the four questions can be grouped in the two large categories of structuralism (material and formal causes) and functionalism (efficient and final causes), with which biologists are most familiar. To put it even more simply: one can ask how things work largely independently of asking why they work that way.

If biology is the pursuit of all of the Aristotelian questions, then we have the answer to our original inquiry: to what extent is integrative biology possible or necessary? From an epistemological standpoint, to completely "understand" something is equivalent to answer all four questions. In this sense, then, integrative biology is a valid pursuit. On the other hand, it should be clear by now that there is plenty of research that can be done within each of these questions without directly addressing the others, if not as ancillary information or background assumptions.

It is perhaps interesting to consider a typical recent case of alleged integrative biology that is, I think, largely misunderstood. It is now routine to present a grant proposal or submit a paper to a journal on, say, the evolution of life history traits, and be asked by reviewers and commentators to add a quantitative trait 
loci study of the possible genes underlying such traits. But while QTL studies are indubitably interesting in and of themselves, we should be clear on the fact that such research endeavor asks a different question from the one of the evolutionary ecology (for example) of certain characters. The answer to why certain plants are winter annuals lies in their ecology, regardless of how many genes allow them to shift to the appropriate life history, where those genes are located, and how they interact with each other.

What I am advocating here is a pluralistic view of biological research, analogous to the one defended by Dupré (1993) based on his criticism of extreme reductionism. Dupré maintains that there is no theoretical or empirical reason to believe in the methodological unity of science, and suggests that the world is fundamentally heterogeneous at the causal level. Indeed, it should be clear from the consideration of nonlinear mathematical theory of physical systems (including biological ones) that old-fashioned reductionism and an actual unification of science is impossible not only pragmatically, but also theoretically even in a completely deterministic universe (Kauffman 1993, Solé et al. 1999). The sensitivity to initial conditions and the emergent properties of complex systems guarantee that we will never reduce molecular biology to quantum physics, so - a fortiori - why should we expect to reduce organismal to molecular biology? More importantly for our discussion, Dupré makes an excellent argument to the effect that knowledge of the lower causal levels of natural phenomena (such as quarks, or genes) only explains how the phenomena at the higher levels (biomolecules, organisms) are possible, but are incapable of allowing us to make predictions of what the higher level phenomena will actually be in any given instance. If Dupré and this author are correct, to look to molecular biology to finally get organismal research out of its quagmire of complexity is like waiting for Godot, and we would be best advised to simply refocus our energy elsewhere.

On the other hand, Dupré's idea of partial decoupling between levels of organization and analysis offers us a new key to understanding integrative biology. Integrative biology is not the (highly misleading and wasteful) effort to reduce organismal to molecular biology, but rather the quest toward a comprehension of the connections among levels of the biological hierarchy, with the understanding that much biology pertains to each level, not to the boundary with other levels.

A pluralistic, rather than forcedly unified, view of biology should prove to be liberating and intellectually fertile. It is liberating because it allows ecologists, evolutionists, molecular biologists, and others to go on with their business without having to keep up with the whole of biological research and still be confident that they will be able to produce significant advancements of knowledge. At the same time, it should be clear from my analysis that there is no philosophical basis on which to assert the primacy of one field of research over another, in the same way in which Aristotle considered an answer to all four basic questions as necessary to fully understand the object of study. The distinctions I suggest should also prove fertile because the true bridges between fields and questions can be pursued without the obsession of an all-encompassing reductionism, but on a level field of mutual aid in the quest for a fully Aristotelian conception of understanding of the natural world.

Acknowledgements. I wish to thank Chris Eckert, Jonathan Kaplan and Courtney Murren for a critical reading of this manuscript and the latter two for discussions on the nature of science. This work was partially supported by NSF grant DEB-0089493.

\section{References}

Ackerly DD (2000) Comparative plant ecology and the role of phylogenetic information. In: Press MC (ed) Plant Physiological Ecology. Blackwell, Oxford, England, pp 391-413.

Alonso-Blanco C, El-Assal SE-D, Coupland G, Koornneef M (1998) Analysis of natural allelic variation at flowering time loci in the Landsberg erecta and Cape Verde Islands ecotypes of Arabidopsis thaliana. Genetics 149: 749-764.

Aristotle (384-322BC) Physics II.3. In Physics, www.wsu.edu/ dee/greece.

Ballarè, CL (1999) Keeping up with the neighbours: phytochrome sensing and other signalling mechanisms. Trends in Plant Science 4: 97-102.

Bell G, Lechowicz MJ (1991) The ecology and genetics of fitness in forest plants. I. Environmental heterogeneity measured by explant trials. Journal of Ecology 79: 663-685.

Callahan H, Pigliucci M (2002) Shade-induced plasticity and its ecological significance in wild populations of Arabidopsis thaliana. Ecology 83: 1965-1980.

Callahan HS, Pigliucci M, Schlichting CD (1997) Developmental phenotypic plasticity: where ecology and evolution meet molecular biology. BioEssays 19: 519-525.

Callahan HS, Wells CL, Pigliucci M (1999) Light-sensitive plasticity genes in Arabidopsis thaliana: mutant analysis and ecological genetics. Evolutionary Ecology Research 1: 731-751.

Camara M, Pigliucci M (1999) Mutational contributions to genetic variance/covariance matrices: an experimental approach using induced mutations in Arabidopsis thaliana. Evolution 53: 1692-1703.

Camara MD, Ancell CA, Pigliucci M (2000) Induced mutations: a novel tool to study phenotypic integration and evolutionary constraints in Arabidopsis thaliana. Evolutionary Ecology Research 2: 1009-1029.

Dixon P, Weinig C, Schmitt, J (2001) Susceptibility to UV damage in Impatiens capensis (Balsaminaceae): testing for 
opportunity costs to shade-avoidance and population differentiation. American Journal of Botany 88: 1401-1408.

Donohue K, Messiqua D, Pyle EH, Heschel MS, Schmitt, J (2001) Evidence of adaptive divergence in plasticity: density- and site-dependent selection on shade-avoidance responses in Impatiens capensis. Evolution 55: 1956-1968.

Dudley SA, Schmitt, J (1996) Testing the adaptive plasticity hypothesis: density-dependent selection on manipulated stem length in Impatiens capensis. The American Naturalist 147: 445-465.

Dupré J (1993) The Disorder of Things: Metaphysical Foundations of the Disunity of Science. Harvard University Press, Cambridge, MA.

Furuya M (1993) Phytochromes: their molecular species, gene families, and functions. Annual Review of Plant Physiology and Molecular Biology 44: 617-745.

Furuya M, Schafer E (1996) Photoreception and signalling of induction reactions by different phytochromes. Trends in Plant Science 1: 301-307.

Gittleman JL, Luh H-K (1992) On comparing comparative methods. Annual Review of Ecology and Systematics 23: 383-404.

Givnish TJ (1982) On the adaptive significance of leaf height in forest herbs. The American Naturalist 120: 353-381.

Grime JP (1974) Vegetation classification by reference to strategies. Nature 250: 26-31.

Grime JP, Crick JC, Rincon JE (1986) The ecological significance of plasticity. In: Jennings DH, Trewavas AJ (eds) Plasticity in plants. Pindar, Scarborough, North Yorkshire, pp 5-29.

Harvey PH, Pagel MD (1991) The Comparative Method in Evolutionary Biology. Oxford University Press, Oxford.

Jones ME (1971) The population genetics of Arabidopsis thaliana. III. The effect of vernalization. Heredity 27: 59-72.

Jonsell B, Kustas K, Nordal I (1995) Genetic variation in Arabis petraea, a disjunct species in northern Europe. Ecography 18: 321-332.

Juenger T, Purugganan M, Mackay TFC (2000) Quantitative trait loci for floral morphology in Arabidopsis thaliana. Genetics 156: 1379-1392.

Kamm A, Galasso I, Schmidt T, Heslop-Harrison JS (1995) Analysis of a repetitive DNA family from Arabidopsis arenosa and relationships between Arabidopsis species. Plant Molecular Biology 27: 853-862.

Kauffman SA (1993) The Origins of Order. Oxford University Press, New York.

Kellogg EA, Shaffer HB (1993) Model organisms in evolutionary studies. Systematic Biology 42: 409-414.

Kingsolver JG, Hoekstra HE, Hoekstra JM, Berrigan D, Vignieri SN, Hill CE, Hoang A, Gibert P, Beerli P (2001) The strength of phenotypic selection in natural populations. American Naturalist 157: 245-261.

Koch M, Bishop J, Mitchell-Olds T (1999) Molecular systematics and evolution of Arabidopsis and Arabis. Plant Biology 1: 529-537.

Koch M, Haubold B, Mitchell-Olds T (2000) Comparative evolutionary analysis of chalcone synthase and alcohol dehydrogenase loci in Arabidopsis, Arabis, and related genera (Brassicaceae). Molecular Biology and Evolution 17: 1483-1498.
Koch M, Haubold B, Mitchell-Olds T (2001) Molecular systematics of the Brassicaceae: evidence from coding plastidic mat $K$ and nuclear $C h s$ sequences. American Journal of Botany 88: 534-544.

Kowalski SP, Lan T-H, Feldmann KA, Paterson AH (1994) QTL mapping of naturally-occurring variation in flowering time of Arabidopsis thaliana. Molecular and General Genetics 245: 548-555.

Kuittinen H, Sillanpaa MJ, Savolainen O (1997) Genetic basis of adaptation: flowering time in Arabidopsis thaliana. Theoretical and Applied Genetics 95: 573-583.

Lande R, Arnold SJ (1983) The measurement of selection on correlated characters. Evolution 37: 1210-1226.

Lechowicz MJ, Bell G (1991) The ecology and genetic of fitness in forest plants. II. Microspatial heterogeneity of the edaphic environment. Journal of Ecology 79: 687-696.

Lee MSY (1999) Circularity, evolution, systematics... and circularity. Journal of Evolutionary Biology 12: 724-734.

Martins EP (2000) Adaptation and the comparative method. Trends in Ecology \& Evolution 15: 296-299.

Mayr E, Provine WB (1980) The evolutionary synthesis. Perspectives on the unification of biology. Harvard University Press, Cambridge, MA.

Mitchell-Olds T (1996) Genetic constraints on life-history evolution: quantitative-trait loci influencing growth and flowering in Arabidopsis thaliana. Evolution 50: 140-145.

Mitchell-Olds T (2001) Arabidopsis thaliana and its wild relatives: a model system for ecology and evolution. Trends in Ecology \& Evolution 16: 693-699.

Napp-Zinn K (1985) Arabidopsis thaliana. In: Halevy AH (ed) CRC Handbook of Flowering. CRC, Boca Raton, FL, pp 492-503.

Omland KE (1999) The assumptions and challenges of ancestral state reconstructions. Systematic Biology 48: 604-611.

Pigliucci M (1998) Ecological and evolutionary genetics of Arabidopsis. Trends in Plant Science 3: 485-489.

Pigliucci M, Schmitt J (1999) Genes affecting phenotypic plasticity in Arabidopsis: pleiotropic effects and reproductive fitness of photomorphogenic mutants. Journal of Evolutionary Biology 12: 551-562.

Pigliucci M, Cammell K, Schmitt J (1999) Evolution of phenotypic plasticity: a comparative approach in the phylogenetic neighborhood of Arabidopsis thaliana. Journal of Evolutionary Biology 12: 779-791.

Pollard H, Cruzan M, Pigliucci M (2001) Comparative studies of reaction norms in Arabidopsis. I. Evolution of response to daylength. Evolutionary Ecology Research 3: 129-155.

Posada D, Crandall KA (2001) Intraspecific gene genealogies: trees grafting into networks. Trends in Ecology \& Evolution 16: 37-45.

Quail PH (1997) The phytochromes: a biochemical mechanism of signaling in sight? BioEssays 19: 571-579.

Rauscher MD (1992) The measurement of selection on quantitative traits: biases due to environmental covariances between traits and fitness. Evolution 46: 616-626.

Rieppel O (1990) Structuralism, functionalism, and the four Aristotelian causes. Journal of the History of Biology 23: 291-320. 
Rohlf FJ (2001) Comparative methods for the analysis of continuous variables: geometric interpretations. Evolution 55: 2143-2160.

Schlichting CD, Pigliucci M (1998) Phenotypic Evolution, a Reaction Norm Perspective. Sinauer, Sunderland, MA.

Schmitt J, Dudley S, Pigliucci M (1999) Manipulative approaches to testing adaptive plasticity: phytochrome-mediated shade avoidance responses in plants. The American Naturalist 154: S43-S54.

Silvertown J (1988) The demographic and evolutionary consequences of seed dormancy. In: Davy AJ, Hutchings MJ, Watkinson AR (eds) Plant Population Ecology. Blackwell, Oxford, England, pp 205-219.

Smith H (2000) Phytochromes and light signal perception by plants - an emergent synthesis. Nature 407: 585-591.

Solé RV, Manrubia SC, Benton M, Kauffman S, Bak P (1999) Criticality and scaling in evolutionary ecology. Trends in Ecology \& Evolution 14: 156-160.

Stratton DA (1995) Spatial scale of variation in fitness of Erigeron annuus. American Naturalist 146: 608-624.

Stratton DA (1998) Reaction norm functions and QTLflowering interactions for flowering time in Arabidopsis thaliana. Heredity 81: 144-155.

Stratton DA, Bennington CC (1996) Measuring spatial variation in natural selection using randomly-sown seeds of
Arabidopsis thaliana. Journal of Evolutionary Biology 9: 215-228.

Stratton DA, Bennington CC (1998) Fine-grained spatial and temporal variation in selection does not maintain genetic variation in Erigeron annuus. Evolution 52: 678-691.

Sturtevant AH (1965) A history of genetics. Harper \& Row, New York, NY.

Tsukaya H, Yokoyama J, Ikeda H, Kuroiwa H, Kuroiwa T, Iwatsuki K (1997) Morphological, physiological and molecular genetic characterization of Arabidopsis himalaica, with reference to A. thaliana. Journal of Plant Research 110: 15-23.

Tucic B, Stojkovic B (2001) Shade avoidance syndrome in Picea omorika seedlings: a growth-room experiment. Journal of Evolutionary Biology 14: 444-455.

Vander-Zwan C, Brodie SA, Campanella JJ (2000) The intraspecific phylogenetics of Arabidopsis thaliana in worldwide populations. Systematic Botany 25: 47-59.

Wagner GP, Altenberg L (1996) Complex adaptations and the evolution of evolvability. Evolution 50: 967-976.

Weinig C (2000) Differing selection in alternative competitive environments: shade-avoidance responses and germination timing. Evolution 54: 124-136.

Westoby M, Leishman MR, Lord JM (1995) On misinterpreting the 'phylogenetic correction'. Journal of Ecology 83: 531-534. 